\title{
Características do professor brasileiro do ensino fundamental: diferenças entre o setor público e o privado
}

\author{
Luiz Guilherme Dácar da Silva Scorzafave*
}

\begin{abstract}
RESUMO - Esse artigo realiza uma análise descritiva de algumas variáveis dos professores do ensino fundamental brasileiro com base nos dados da RAIS. De forma geral, verificou-se que os professores do ensino fundamental perceberam aumentos reais, em média, na sua remuneração mensal no período 1999-2010. Entretanto, os maiores aumentos percentuais ocorreram para professores com nível médio e superior de escolaridade. Percebeu-se também um aumento na qualificação média do professor do ensino fundamental. Por fim, verificou-se que as redes estaduais e municipais pagavam em 2010 salários substancialmente maiores (57\% e 29\%, respectivamente), em média, que os da rede privada de ensino fundamental, colocando em xeque o senso comum de que os professores da rede pública recebem menores salários que os da rede privada.
\end{abstract}

Palavras-chave: Professor. Salários. Setor público. Escola pública. Escola privada.

\section{INTRODUÇÃO}

Nos últimos anos a questão da educação vem ganhando cada vez mais espaço na sociedade brasileira. Parece estar se formando um consenso acerca da importância da educação para o desenvolvimento do país. Apesar de constituir um considerável avanço por si só, essa maior conscientização está longe de ser suficiente para garantir uma efetiva melhoria do nível de ensino das crianças brasileiras. Em particular, é necessário um maior entendimento sobre os meios que possibilitem essa melhora do ensino. Embora já haja alguns trabalhos buscando identificar o efeito causal de fatores específicos sobre a proficiência dos alunos do ensino fundamental brasileiro, ainda há diversas lacunas a serem preenchidas.

Desse modo, o presente trabalho pretende servir como incentivo para que novas pesquisas possam ser feitas, enfocando-se o papel dos professores nesse processo. Assim, antes de identificar que características do professor mais afetam a proficiência dos alunos, é importante estabelecer um retrato mais detalhado desse profissional. Quais suas características, como elas têm evoluído ao longo do tempo, como ele se insere no mercado de trabalho etc. Desse modo, a construção desse perfil mais detalhado se constitui em passo inicial, todavia importante, para uma melhor compreensão acerca do papel do professor sobre os resultados escolares dos alunos brasileiros.

Em particular, o artigo joga uma luz à questão da diferenciação entre professores da

\footnotetext{
* Doutor em Economia pela Universidade de São Paulo. É professor da Universidade de São Paulo. Endereço eletrônico: scorza@usp.br.
} 
rede pública e privada. Os resultados encontrados contrariam o senso comum de que os salários médios da rede privada são maiores que os da rede pública. Apenas esse resultado surpreendente já pode servir como ponto de partida para pesquisas futuras que procurem compreender melhor as causas e consequências dessa diferença.

\section{DADOS E METODOLOGIA}

Os dados relativos a presente pesquisa são oriundos da Relação Anual de Informações Sociais (RAIS), registro administrativo do Ministério do Trabalho e Emprego, que apresenta a situação, ao término de cada ano, dos trabalhadores com registro formal de emprego, sejam esses do setor público ou do setor privado. O Ministério disponibiliza esses dados em formato de CD-ROM de modo que é possível construir diferentes recortes de amostra, de acordo com o estudo de interesse, através da tabulação cruzada das variáveis contidas na RAIS. Em particular, o presente trabalho buscou analisar detalhadamente diversos recortes associados à categoria ocupacional "professor", especificamente aquele lecionando no ensino fundamental. Apesar de termos realizado um esforço de compatibilizar os dados da RAIS no período 1985-2008, não foi possível realizar todas as análises para esse intervalo de tempo, devido a mudanças no questionário da pesquisa, que inviabilizam algumas comparações ao longo do tempo. Portanto, para as análises em que esse tipo de problema ocorreu, buscou-se trabalhar apenas nos dados mais recentes.

Com relação à metodologia, o trabalho se apresenta como uma análise descritiva de diversas dimensões da ocupação de professor do ensino fundamental no Brasil. A ideia é enfatizar a evolução temporal, avaliando não somente a situação presente, mas também a situação passada, que permite o desenho de como esse profissional vem mudando ao longo do tempo no país. Dentre as características analisadas, destaca-se a remuneração média de acordo com grau de escolaridade do professor e com relação ao sistema de ensino no qual o docente está inserido. Além disso, é analisada a evolução temporal da distribuição dos professores de acordo com a escolaridade dos mesmos e com relação à rede de ensino. Por fim, também são apresentadas informações quanto a duração da jornada de trabalho desses profissionais. Como ressaltado anteriormente, espera-se que essa análise descritiva possa gerar subsídios para uma melhor compreensão do papel do professor no processo de melhoria das condições de ensino no Brasil. 


\section{RESULTADOS}

\subsection{REMUNERAÇÃO DOS PROFESSORES DE ACORDO COM A ESCOLARIDADE}

Inicialmente, é apresentada a remuneração média mensal dos professores de acordo com a escolaridade dos mesmos. A motivação para essa apresentação é que se perceba como tem evoluído a remuneração real dos docentes do ensino fundamental brasileiro no sentido de averiguar se as condições de remuneração vêm melhorando ou não ao longo do tempo. As limitações metodológicas da base da RAIS permitem a realização desse recorte de análise apenas a partir de 1999. Os dados foram deflacionados a partir do IPCA/IBGE e são apresentados em valores reais de dezembro de 2010.

\section{GRÁFICO 1 - EVOLUÇÃO DA REMUNERAÇÃO MENSAL DOS PROFESSORES DO ENSINO FUNDA- MENTAL POR NÍVEIS DE ESCOLARIDADE - 1999-2010}

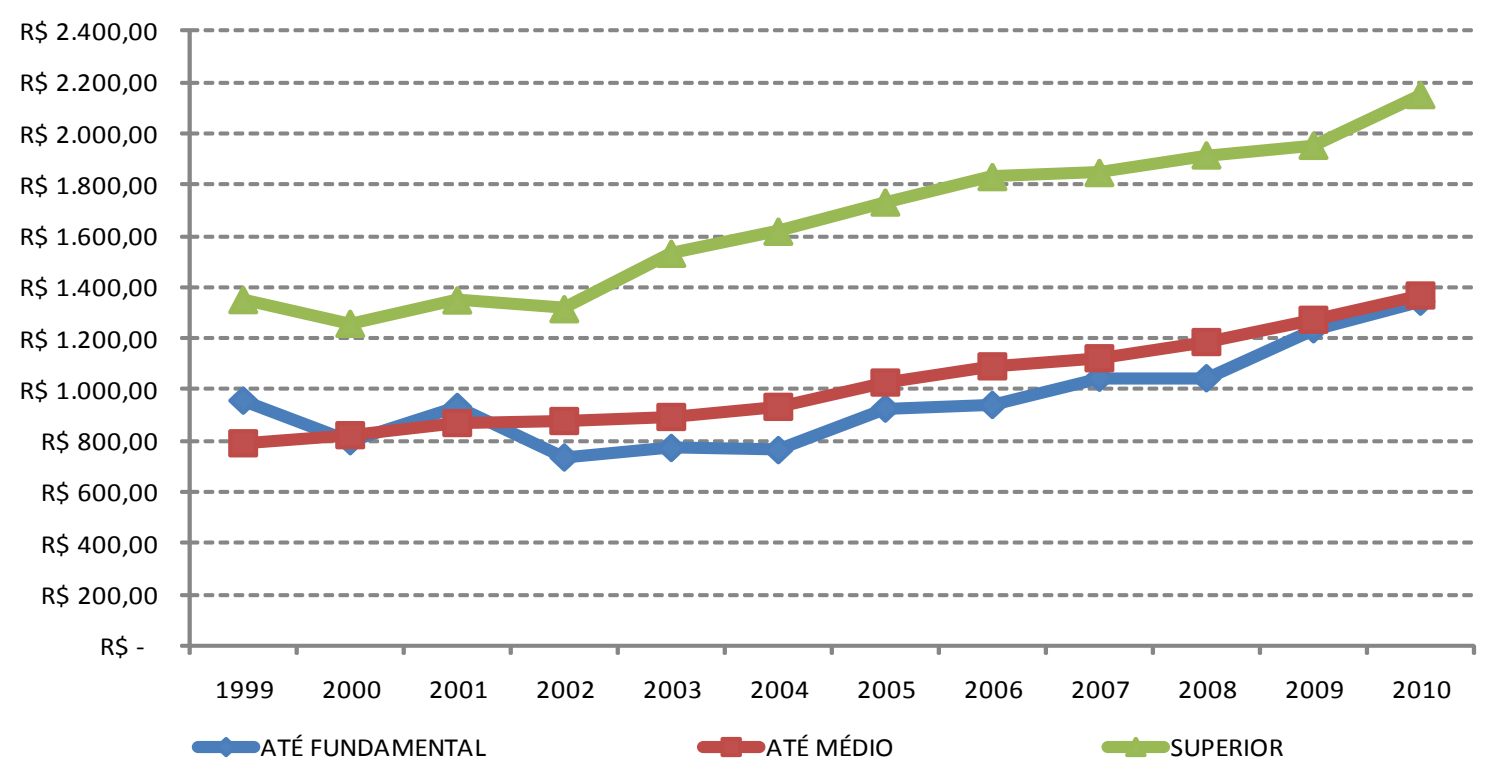

FONTE: Elaboração própria com base nos dados da RAIS.

Os dados apresentados no Gráfico 1 permitem afirmar que os professores com algum ensino superior (mesmo que incompleto) são aqueles que perceberam maiores aumentos absolutos de salários no período, de cerca de $\mathrm{R} \$ 800,00$ mensais, uma elevação de $59 \%$ sobre os salários de 1999. Cabe destacar também que essa melhor evolução se deu a partir de 2003, pois até então, o salário estava praticamente estagnado em termos reais. Por sua vez, os docentes com ensino médio (completo ou incompleto) perceberam os maiores aumentos salariais relati$\operatorname{vos}(72 \%)$ em termos reais sobre os valores de 1999, embora continuassem ganhando remuneração, em média, 38\% menor que a dos docentes com nível superior. Por fim, os docentes com 
ensino fundamental (completo ou incompleto) perceberam aumento real de salários menor no período, em relação àqueles com ensino médio e superior, recebendo 40\% a mais em 2010 do que recebiam em 1999. Esses docentes, entretanto, vêm em um lento processo de ganho salarial real desde 2004, embora não suficiente para compensar as oscilações de renda do período entre 1999 e 2010.

A seguir, avaliamos a evolução dos salários médios por rede de ensino no período 1999-2010.

GRÁFICO 2 - EVOLUÇÃO DA REMUNERAÇÃO MENSAL DOS PROFESSORES DO ENSINO FUNDAMENTAL POR REDE DE ENSINO - 1999-2008

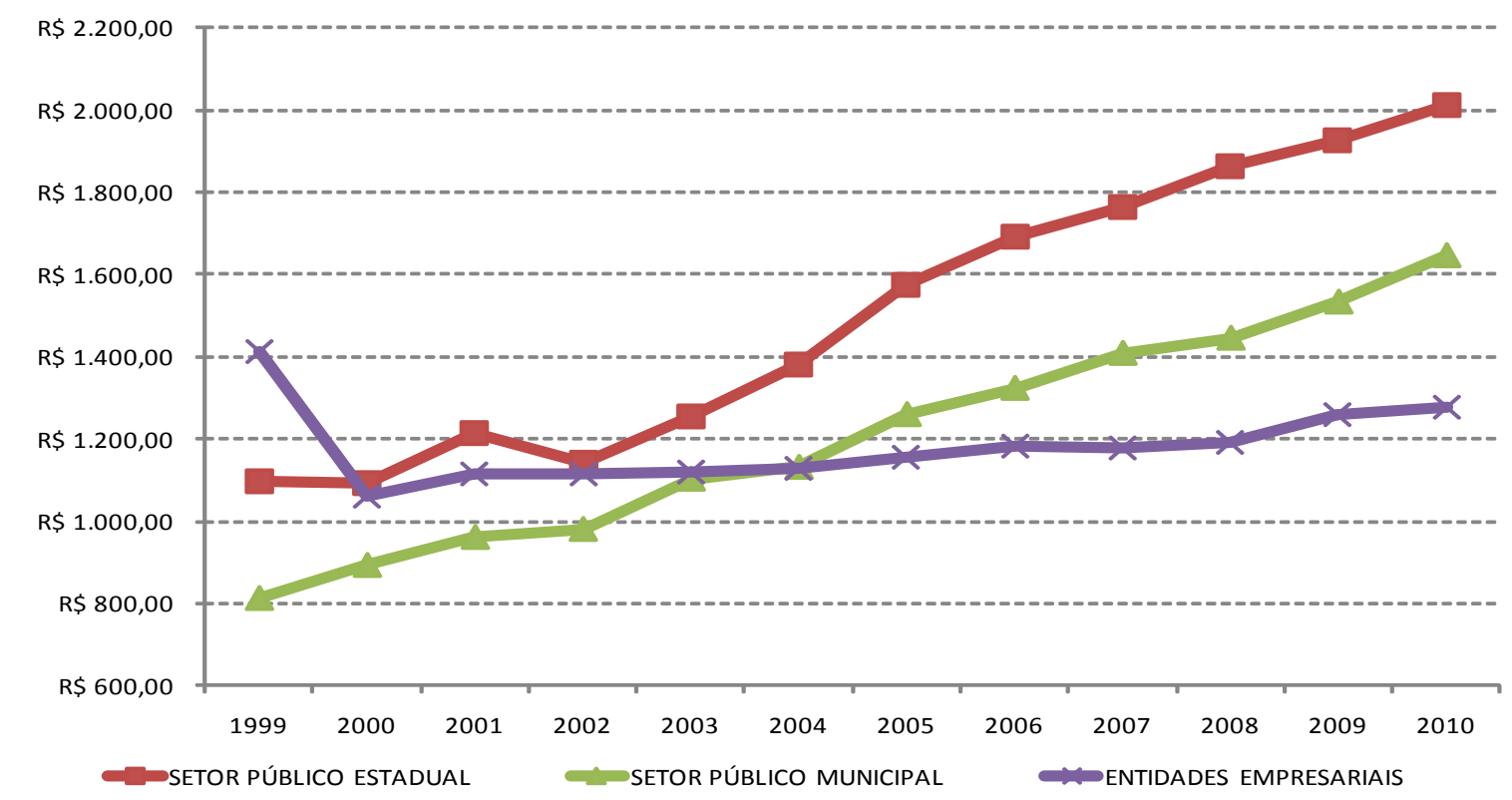

FONTE: Elaboração própria com base nos dados da RAIS.

Os dados referentes à remuneração média por rede de ensino são surpreendentes. As escolas privadas mantiveram a remuneração real praticamente constante no período 2000-2010. Por sua vez, os professores das redes estaduais perceberam grandes aumentos reais de salário (84\% em termos reais), o que também ocorreu, com grande magnitude, para professores das redes municipais (103\% em termos reais). Esse panorama leva a um retrato de remuneração muito diferenciado entre o setor público e privado no ensino fundamental brasileiro em 2010, com o salário médio da rede privada equivalendo a quase 64\% daquele das redes estaduais! Assim, fica claro que o senso comum de que o salário médio dos professores da rede pública é menor que o da rede privada não é correto. 


\subsection{DISTRIBUIÇÃO DE PROFESSORES DE ACORDO COM A ESCOLARIDADE}

No que tange à distribuição dos professores de acordo com a escolaridade, o panorama do período apresenta transformações bem mais aprofundadas do que aquelas relacionadas ao comportamento salarial. O Gráfico 3 apresenta a evolução temporal desse indicador desde 1985.

GRÁFICO 3 - DISTRIBUIÇÃO DE PROFESSORES DO ENSINO FUNDAMENTAL POR ESCOLARIDADE -1985-2010

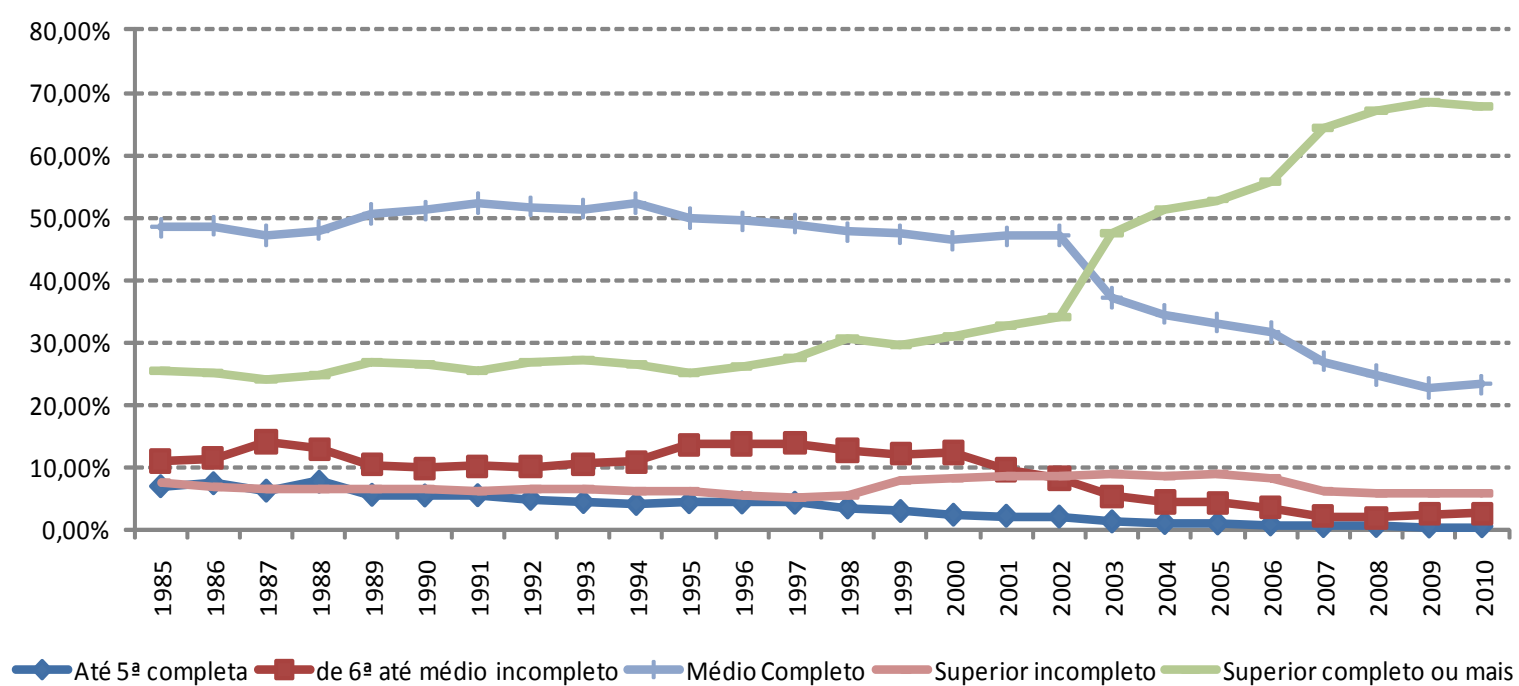

FONTE: Elaboração própria com base nos dados da RAIS.

Percebe-se claramente uma estabilidade até 1996, quando se inicia um lento declínio da proporção de docentes com ensino médio completo e uma também suave elevação dos docentes com superior (completo e incompleto). Esse movimento se acentua a partir de 2002, havendo um forte aumento de escolaridade entre os docentes do ensino fundamental.

\subsection{JORNADA DE TRABALHO E SALÁRIO HORÁRIO DOS PROFESSORES}

Agora, serão analisadas a jornada de trabalho e o salário horário médio dos professores. Para esses indicadores, os dados da RAIS também permitem uma separação por setor onde a escola se insere. Assim, apresentamos os resultados desagregados para as redes de ensino (estadual, municipal e privada).

Em termos de jornada de trabalho, verifica-se uma dinâmica diferenciada no período. De 1999 até 2005 houve uma contínua e suave elevação das horas trabalhadas por semana dos professores da rede estadual, chegando ao pico de pouco mais de 35 horas em 2005. A partir de então, esse valor experimenta uma queda brusca, ficando praticamente estável em 32 horas nos anos de 2009 e 2010. Pode-se especular, aqui, que essa redução pode estar associada a um 
possível efeito renda. Como houve um aumento real do total dos rendimentos do trabalho dos professores e como o número de horas trabalhadas vem diminuindo desde 2005, deve estar ocorrendo desde então uma elevação na hora-aula dos docentes. Assim, muitos podem ter optado por responder a essa elevação da taxa de salário através de uma redução do número de horas de trabalho, caso em que o efeito renda do aumento da taxa salarial seria maior que o efeito substituição.

Já os professores que atuam junto as entidades privadas, de 1999 a 2007 trabalhavam por volta de 25 horas semanais. Todavia, a partir de então experimentaram uma elevação de, aproximadamente, $12 \%$ nas horas trabalhadas por semana, uma vez que a partir de 2008 passaram a trabalhar 28 horas por semana. Por fim, verifica-se no gráfico abaixo que os professores da rede municipal mantiveram quase que inalteradas a jornada média semanal de trabalho, no patamar de cerca de 30 horas semanais.

GRÁFICO 4 - JORNADA SEMANAL DE TRABALHO MÉDIA DOS PROFESSORES DO ENSINO FUNDAMENTAL BRASILEIRO POR REDE DE ENSINO - 1999-2010

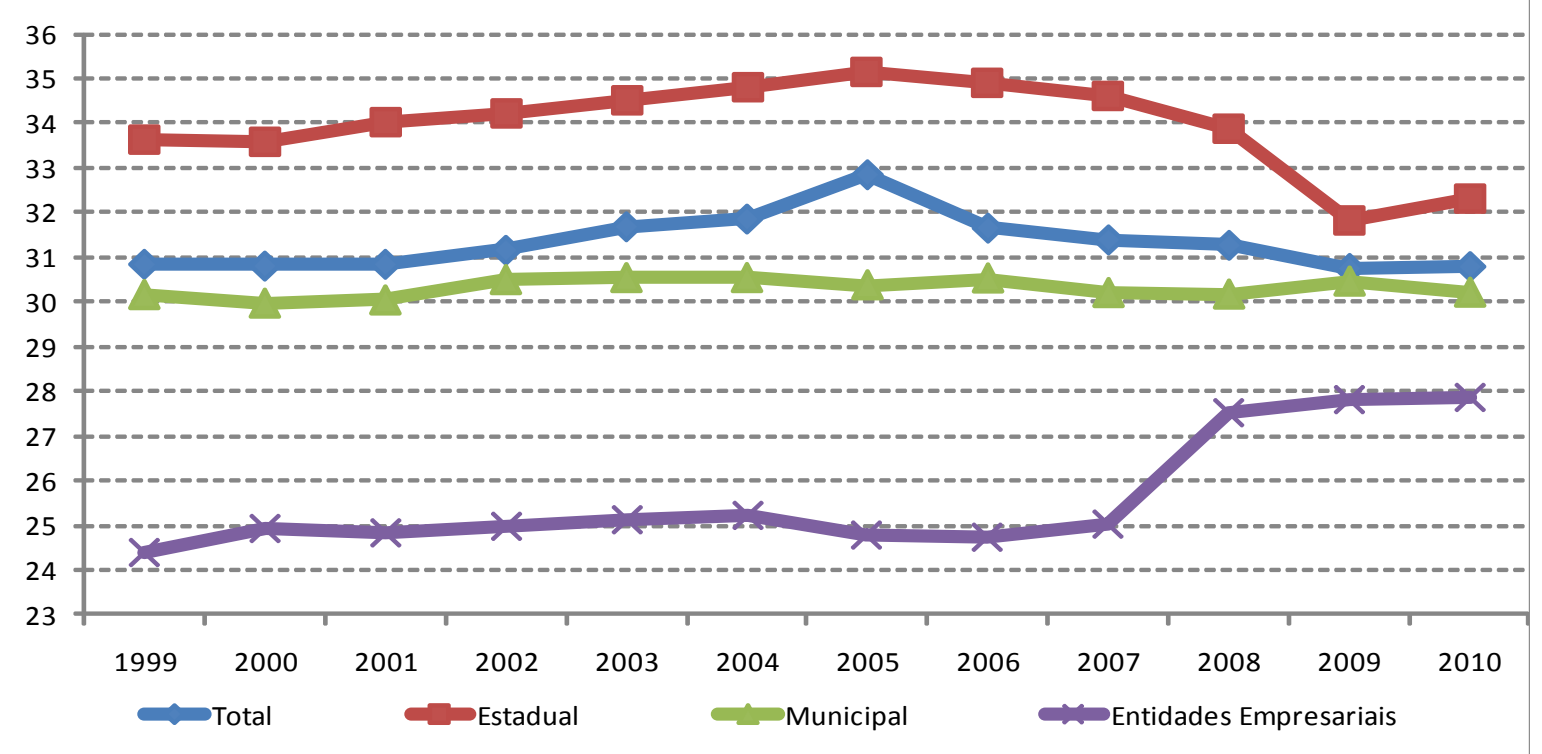

FONTE: Elaboração própria com base nos dados da RAIS.

Na subseção anterior, realizou-se uma análise sobre a evolução da remuneração média mensal dos professores por rede de ensino, evidenciando uma renda maior para os professores da rede pública. Uma crítica a esse resultado é que ele não levaria em conta o fato de que a jornada semanal de trabalho é menor na rede privada do que na pública.

Assim, é interessante destacar a evolução da remuneração por hora trabalhadas desses profissionais, pois pode ser que o professor da rede pública compense sua baixa remuneração por hora trabalhada justamente aumentando sua jornada. O gráfico a seguir apresenta o salário 
horário, e o panorama sofreu mudanças importantes ao longo do tempo.

Atualmente, os professores da rede pública recebem melhores salários, mas a história nem sempre foi assim. Foi apenas em 2006 que a remuneração dos professores da rede estadual superou a daqueles das entidades privadas. Já dois anos depois, essa foi ultrapassada pela remuneração média por hora trabalhada dos professores da rede municipal. Vale mencionar que, enquanto o salário médio dos professores das entidades empresariais segue uma tendência de estagnação, aqueles que atuam nas redes públicas de ensino vêm percebendo contínuas melhorias salariais.

GRÁFICO 5 - SALÁRIO HORÁRIO DOS PROFESSORES DO ENSINO FUNDAMENTAL BRASILEIRO POR REDE DE ENSINO - 1999-2010

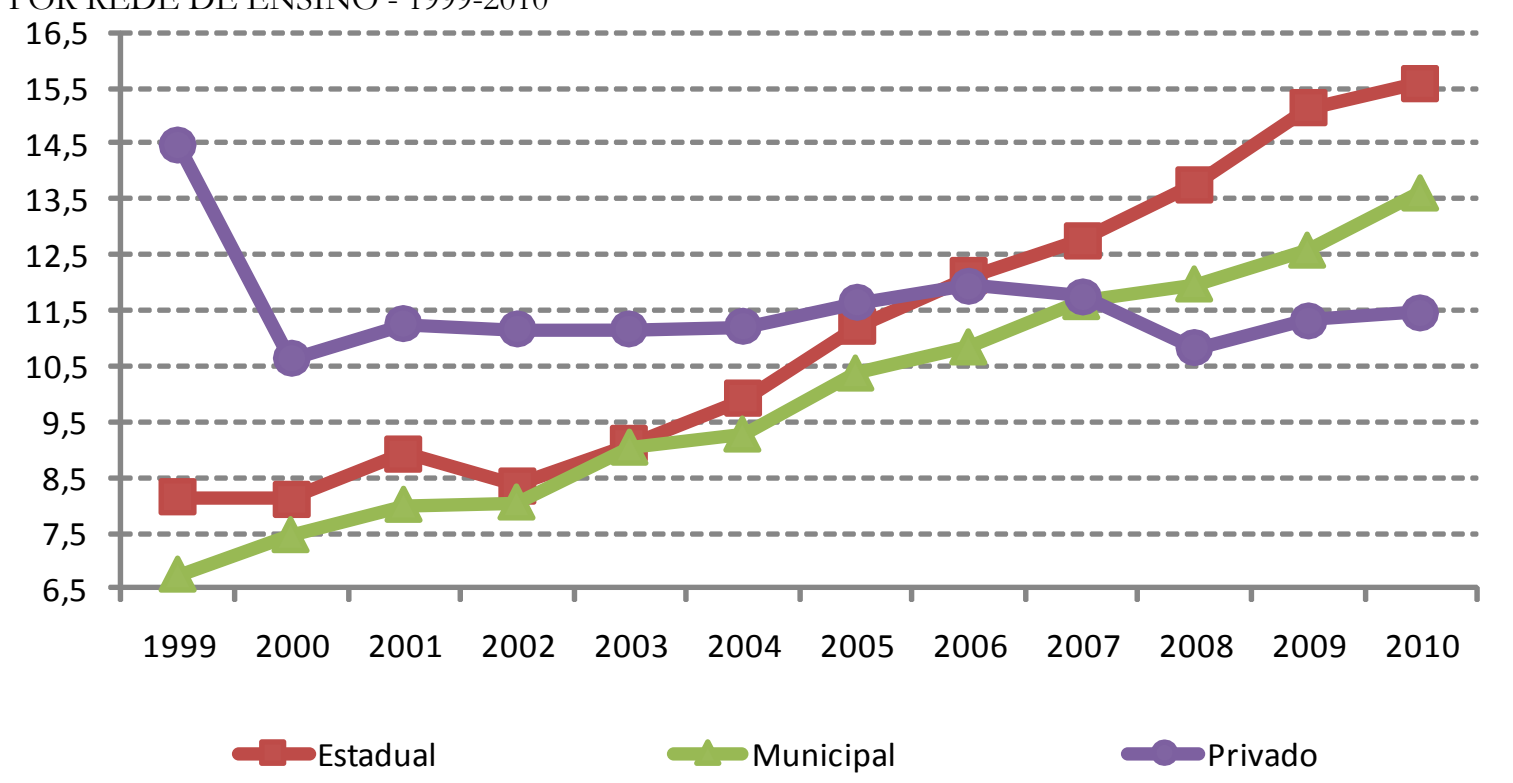

FONTE: Elaboração própria com base nos dados da RAIS.

Assim, fica claro que para os docentes da rede estadual o movimento de elevação do salário horário e de diminuição da jornada semanal de trabalho culminou em uma maior remuneração mensal. Para aqueles que lecionam na rede municipal, houve um aumento salarial não acompanhado por mudanças significativas em sua jornada de trabalho. Entretanto, cabe destacar que os professores das entidades empresarias não auferiram os mesmos benefícios que os anteriores, pois houve elevação da jornada de trabalho e estabilidade no valor do salário horário desde 2000.

\section{CONSIDERAÇÕES FINAIS}

O presente trabalho procurou traçar um perfil do professor de ensino fundamental no Brasil com base nos dados da Relação Anual de Informações Sociais (RAIS). Devido a 
diferentes perguntas do questionário da RAIS, não foi possível, em todas as análises, recuperar as informações referentes ao período 1985-2010. Entretanto, a partir de 1999, há certa uniformidade nos quesitos investigados, de modo que foi possível desenhar mais nitidamente esse retrato do docente brasileiro do ensino fundamental, bem como as alterações sofridas ao longo do tempo. O objetivo do presente trabalho foi meramente realizar uma análise descritiva, sem uma preocupação de se inferir relações de causalidade entre as variáveis analisadas. Neste sentido, as conclusões dessa pesquisa devem servir como pano de fundo para levantar novos questionamentos acerca dos fatores que estão afetando a carreira do professor de ensino básico no Brasil e, por conseguinte, afetando também o próprio desempenho dos alunos.

De forma geral, verificou-se que os professores do ensino fundamental perceberam aumentos reais, em média, na sua remuneração mensal no período 1999-2010. Entretanto, os maiores aumentos percentuais ocorreram para professores com nível médio e superior de escolaridade. Percebeu-se também um aumento na qualificação média do professor do ensino fundamental. Por fim, verificou-se que o salário médio das redes estaduais ou municipais de ensino eram, em 2010, substancialmente maiores que o da rede privada $(57 \%$ e $29 \%$, respectivamente), colocando em xeque o senso comum de que os professores da rede pública são pior remunerados que os colegas de profissão da rede privada.

\section{REFERÊNCIAS}

RELAÇÃO ANUAL DE INFORMAÇÕES SOCIAIS (RAIS). Brasília: Ministério do Trabalho e Emprego, 1985-2008. 1 CD-ROM. 